\title{
Outcomes and Resource Utilization in Calcium Pyrophosphate Deposition Disease Patients Who Underwent Total Knee Arthroplasty: A Retrospective Cohort Analysis.
}

\section{Konstantinos Parperis ( $\sim$ kparpe02@ucy.ac.cy)}

University of Cyprus Medical School: Panepistemio Kyprou latrike Schole https://orcid.org/0000-00016009-0130

\section{Mohanad Hadi}

Valleywise Health Medical Center

\section{Bikash Bhattarai}

Valleywise Health Medical Center

\section{Research article}

Keywords: calcium pyrophosphate deposition disease, chondrocalcinosis, CPPD, knee arthroplasty, knee replacement, healthcare utilization, charges, length of stay.

Posted Date: November 9th, 2021

DOI: https://doi.org/10.21203/rs.3.rs-1044767/v1

License: () (i) This work is licensed under a Creative Commons Attribution 4.0 International License.

Read Full License 


\section{Abstract}

Background: To evaluate the predictors, outcomes and resource utilization of total knee arthroplasty (TKA) in calcium pyrophosphate deposition disease (CPPD) patients.

Methods: We used the US National Inpatient Sample database to identify CPPD and non-CPPD who underwent TKA from 2006 to 2014. Data collection included patient demographics and comorbidities. Outcomes following TKA included in-hospital mortality, complications, length of hospitalization, hospital charges, and disposition.

Results: Among the 5,564,005 patients who have undergone TKA, $11529(0.20 \%)$ had CPPD, with a median age of 72 years and $53.7 \%$ were females. Compared with non-CPPD, patients with CPPD were more likely to be older (mean: 72 vs 66 years; $p<0.001$ ), male, white, and have Medicare insurance. CPPD patients were more likely to have $\geq 2$ comorbidities calculated by the Charlson comorbidity index and discharge to an inpatient/rehabilitation facility. Regarding inpatient complications, myocardial infarction and knee reoperation were significantly more common in CPPD patients. TKA in CPPD patients was associated with significantly higher odds of increased length of stay ( $>3$ days) than those without CPPD (OR $1.43,95 \% \mathrm{Cl} 1.37-1.49$ ). There was no significant difference in the in-hospital mortality.

Conclusions: CPPD patients who underwent TKA were more likely to have a longer hospital stay and discharge to a non-home setting than non-CPPD. Also, CPPD patients had a higher comorbidity burden, and greater risk for myocardial infarction and need for reoperation.

\section{Background}

Calcium pyrophosphate deposition (CPPD) disease is a common crystal-induced arthropathy, characterized by the deposition of calcium pyrophosphate crystals (CPP) in the articular and periarticular tissues, that might lead to inflammatory arthritis, joint damage, impairment, and disability [1]. Chondrocalcinosis, defined as calcification of the cartilage, is a common radiographic finding in patients with CPPD can be associated with symptoms of arthritis or can be asymptomatic [2,3]. The estimated prevalence of CPPD is unknown; however, the prevalence of chondrocalcinosis ranges from $7-10 \%$ and often affects older patients [2-4]. Advance age remains the most common risk factor for the development of CPPD, followed by several metabolic conditions, including hyperparathyroidism, hypomagnesemia, hemochromatosis and hypophosphatasia [5].

CPPD may mimic any rheumatic disease with the following clinical presentations: an asymptomatic form, acute calcium pyrophosphate dihydrate (CPP) crystal arthritis, which is characterized by episodes of monoarthritis, chronic CPP crystal arthritis affecting multiple joints and osteoarthritis associated with CPPD [6]. Management includes physical therapy, colchicine, NSAIDs, glucocorticoids, and in patients with severe knee pain due to destruction of cartilage, total knee arthroplasty (TKA) is an effective and safe procedure [7]. 
In the United States, approximately 600,000 TKA are performed each year, and there are scant data on TKA in CPPD patients. A previous study demonstrated that $20 \%$ of patients who underwent TKA were found to have CPP or basic calcium phosphate crystals in the synovial fluid [8]. A cross-sectional study using the Veterans Affairs database showed that knee arthroplasties were more common in the CPPD cohort compared with the control group ( $12.2 \%$ vs. $6.7 \%)$ even after controlling for the presence of osteoarthritis in the multivariate model $(\mathrm{OR} 1.64 ; 95 \% \mathrm{Cl}, 1.53-1.76)$ [9]. A retrospective cohort study of patients with end-stage osteoarthritis undergoing TKA, showed no difference in regard to pain, functionality and postoperative complications between patients with and without chondrocalcinosis [10].

To date, there are few studies evaluating the clinical outcomes and health care burden of patients with CPPD disease treated with TKA. The aim of this study was to determine the patient characteristics, predictors, in-hospital mortality, complications, and resource utilization following TKA in patients with and without CPPD.

\section{Methods}

This a cross-sectional study conducted analyzing data from the National Inpatient Sample (NIS) Database from 2006-2014. NIS is a part of the Healthcare Cost and Utilization Project (HCUP) by the Agency for Healthcare Research and Quality [11]. The NIS is the largest all-payer inpatient database in the USA, with recorded de-identified data of more than 7 million hospitalizations annually, and it approximates a $20 \%$ stratified sample of all US hospital discharges. Data recorded include the discharge diagnosis, comorbid conditions, procedures, length of stay, total hospital costs, and outcomes measures.

International Classification of Diseases code, ninth revision (ICD-9) was used to identify all patients who underwent TKA (V43.65) from 2006-2014, and of those we scrutinized the ICD-9 codes defining CPPD (275.49 and 712.1-39). A previous study demonstrated the use of the aforementioned codes have a positive predictive value of $91 \%$ to identify CPPD patients; therefore, it is a reliable method to identify clinical definitive or probable CPPD [12]. Therefore, we included all patients who had TKA, with and without CPPD.

Data collection included patient demographics, such as age, gender, ethnicity, insurance, median household income for patient's zip code. Information regarding the hospitals included the region (Northeast, Midwest, South, West), bed size and location (rural, urban or other). Comorbidities such as diabetes, chronic liver and renal disease, obesity, osteoarthritis, rheumatoid arthritis, gout, avascular necrosis, hemochromatosis, hyperparathyroidism, hypomagnesemia, hypophosphatasia and history smoking were identified using the ICD-9 codes. A validated tool to predict mortality in patients with comorbidities, the Deyo adaptation of the Charlson comorbidity index, was used [13].

Demographic factors summarized include age, gender, race, insurance type, comorbidities, and discharge disposition along with hospital features. The primary outcomes assessed were in-hospital mortality of CPPD patients undergoing TKA, the length of hospital stay, and total hospital charges. Secondary outcomes included Charlson comorbidity index, postoperative complications such as surgical site 
infections, blood loss and need for transfusion, reoperation, thromboembolism, myocardial infarction, popliteal artery injury, peroneal nerve palsy. The postoperative course includes discharge to home (with or without home care) versus other facilities such as rehabilitation units, skilled nursing facilities, short, intermediate and long-term care facility or hospital. All the outcomes were compared with a cohort of non-CPPD patients who underwent TKA. Very few variables had missing values leading to less than the total number of patients summarized.

\section{Statistical analysis}

We evaluated the association between each of categorical factors with CPPD vs non-CPPD groups using $\chi 2$ tests. Some continuous variables were dichotomized (e.g., length of hospital stay above and below the median of 3 days) for effective presentation. Some of the patient features as well as in-hospital complication measures were continuous variables, which were compared using Wilcoxon rank sum test. A p-value $<0.05$ was regarded as statistically significant. We have also presented odds ratio (and $95 \%$ confidence intervals) for death among total knee replacement patients with and without CPPD as the most severe outcome. Further, we examined the proportion of TKA per year in CPPD patients compared with the non-CPPD Using Cochran-Armitage trend test. Statistical analyses were conducted using SAS (Version 9.4, www.sas.com)

\section{Results}

Patient characteristics with and without CPPD who underwent TKA are presented in detail in Table 1. Among the 5,564,005 (adjusted for sampling weight) TKA patients, 11,529 $(0.20 \%)$ had CPPD, with a mean age of 72 years, $53.7 \%$ were females, and $73.1 \%$ were white. Compared with non-CPPD patients, those with CPPD patients were significantly older (median age 72 vs 66 years old, $p<0.001$ ), and $18.8 \%$ were above the age of 80 versus $9.7 \%$ in the non-CPPD $(p<0.001)$. Additionally, CPPD patients were more likely to be male $(p<0.001)$, white $(p<0.001)$ and have Medicare insurance $(p<0.001)$. TKA in CPPD patients was more often performed in a large hospital (based on the number of beds, $p<0.001$ ), located in the Western US $(p<0.001)$, and patients were more likely to live in the highest household income category (76-100th percentile) $(27.9 \%$ vs $23.8 \%$; $p<0.001$, Table 1$)$. 
Table 1

General characteristics of patients with and without CPDD who underwent total knee arthroplasty from 2006 to 2014.

\begin{tabular}{|c|c|c|c|c|}
\hline \multirow[t]{2}{*}{ Variables } & \multirow{2}{*}{$\begin{array}{l}\text { All patients } \\
\mathrm{N}=5,564,005\end{array}$} & \multirow{2}{*}{$\begin{array}{l}\text { No CPDD } \\
\mathrm{N}=5,552,476\end{array}$} & \multirow{2}{*}{$\begin{array}{l}\text { CPDD } \\
\mathrm{N}=11,529\end{array}$} & \multirow{2}{*}{$\begin{array}{l}\mathrm{P} \text { - } \\
\text { value }\end{array}$} \\
\hline & & & & \\
\hline Age, mean \pm SD year, median & $\begin{array}{l}66.1 \pm 22.73 \\
66.00\end{array}$ & $\begin{array}{l}66.09 \pm 22.73 \\
66.00\end{array}$ & $\begin{array}{l}70.34 \\
\pm 22.27,72\end{array}$ & $<0.001$ \\
\hline Age group (\%) & & & & $<0.001$ \\
\hline Age less than 50 & 295251 & $294,967(5.31)$ & $284(2.46)$ & \\
\hline Age $50-64$ & 2096374 & $\begin{array}{l}2,093,550 \\
(37.7)\end{array}$ & $\begin{array}{l}2,824 \\
(24.49)\end{array}$ & \\
\hline Age 65-79 & 2631492 & $\begin{array}{l}2,625,243 \\
(47.28)\end{array}$ & $6,249(54.2)$ & \\
\hline Age above than 80 & 540888 & $538,716(9.7)$ & $\begin{array}{l}2,172 \\
(18.84)\end{array}$ & \\
\hline Gender, n (\%) & & & & $<0.001$ \\
\hline Male & 2068722 & $\begin{array}{l}2,063,394 \\
(37.16)\end{array}$ & $\begin{array}{l}5,328 \\
(46.21)\end{array}$ & \\
\hline Female & 3486076 & $\begin{array}{l}3,479,875 \\
(62.67)\end{array}$ & $\begin{array}{l}6,201 \\
(53.79)\end{array}$ & \\
\hline Race & & & & $<0.001$ \\
\hline White & 3927344 & $\begin{array}{l}3,918,915 \\
(70.58)\end{array}$ & $\begin{array}{l}8,429 \\
(73.11)\end{array}$ & \\
\hline Black & 350986 & $350,543(6.31)$ & $442(3.83)$ & \\
\hline Hispanic & 252844 & $252,318(4.54)$ & $526(4.56)$ & \\
\hline Asian or Pacific Islander & 59022 & $58,936(1.06)$ & $86(0.75)$ & \\
\hline Native American & 23402 & $23,363(0.42)$ & $39(0.34)$ & \\
\hline Other & 106253 & $106,042(1.91)$ & $211(1.83)$ & \\
\hline Primary payer ( 6 categories) & & & & $<0.001$ \\
\hline Medicare & 3056686 & $\begin{array}{l}3,048,844 \\
(54.91)\end{array}$ & $\begin{array}{l}7,842 \\
(68.02)\end{array}$ & \\
\hline Medicaid & 163462 & $163,261(2.94)$ & $200(1.73)$ & \\
\hline
\end{tabular}

*All others include transfer to nursing facility, rehabilitation facility and short, intermediate, long-term care hospital or facility, hospice medical facility, against medical advice, federal health facility. CCl: Charlson Comorbidity Index. 


\begin{tabular}{|c|c|c|c|c|}
\hline \multirow[t]{2}{*}{ Variables } & \multirow{2}{*}{$\begin{array}{l}\text { All patients } \\
\mathrm{N}=5,564,005\end{array}$} & \multirow{2}{*}{$\begin{array}{l}\text { No CPDD } \\
\mathrm{N}=5,552,476\end{array}$} & \multirow{2}{*}{$\begin{array}{l}\text { CPDD } \\
N=11,529\end{array}$} & \multirow{2}{*}{$\begin{array}{l}\mathrm{P} \text { - } \\
\text { value }\end{array}$} \\
\hline & & & & \\
\hline Private insurance & 2118451 & $\begin{array}{l}2,115,295 \\
(38.1)\end{array}$ & $\begin{array}{l}3,156 \\
(27.37)\end{array}$ & \\
\hline Self-pay & 24615 & $24,576(0.44)$ & $39(0.34)$ & \\
\hline No charge & 4631 & $4,631(0.08)$ & $0(0)$ & \\
\hline Other & 184018 & $183,756(3.31)$ & $262(2.27)$ & \\
\hline $\begin{array}{l}\text { Median Household Income for } \\
\text { Patient's ZIP Code }\end{array}$ & & & & $<0.001$ \\
\hline 0-25th percentile & 1210163 & $\begin{array}{l}1,208,030 \\
(21.76)\end{array}$ & 2,133 (18.5) & \\
\hline 26th to 50 th percentile & 1481018 & $\begin{array}{l}1,477,920 \\
(26.62)\end{array}$ & $\begin{array}{l}3,098 \\
(26.87)\end{array}$ & \\
\hline 51st to 75 th percentile & 1447852 & $\begin{array}{l}1,444,921 \\
(26.02)\end{array}$ & $\begin{array}{l}2,931 \\
(25.42)\end{array}$ & \\
\hline 76th to 100 th percentile & 1327122 & $\begin{array}{l}1,323,905 \\
(23.84)\end{array}$ & $3,217(27.9)$ & \\
\hline Hospital region & & & & $<0.001$ \\
\hline Northeast & 934474 & $\begin{array}{l}932,503 \\
(16.79)\end{array}$ & $1,971(17.1)$ & \\
\hline Midwest & 1534285 & $\begin{array}{l}1,531,040 \\
(27.57)\end{array}$ & $\begin{array}{l}3,245 \\
(28.15)\end{array}$ & \\
\hline South & 2030583 & $\begin{array}{l}2,027,270 \\
(36.51)\end{array}$ & $\begin{array}{l}3,313 \\
(28.74)\end{array}$ & \\
\hline West & 1064662 & $\begin{array}{l}1,061,662 \\
(19.12)\end{array}$ & $\begin{array}{l}3,000 \\
(26.02)\end{array}$ & \\
\hline Hospital location & & & & 0.026 \\
\hline Rural & 443187 & $442,176(7.96)$ & $1,011(8.77)$ & \\
\hline Urban & 3124309 & $\begin{array}{l}3,117,698 \\
(56.15)\end{array}$ & $\begin{array}{l}6,611 \\
(57.34)\end{array}$ & \\
\hline Other/missing & 1996509 & $\begin{array}{l}1,992,601 \\
(35.89)\end{array}$ & 3,908 (33.9) & \\
\hline Hospital bed size & & & & $<0.001$ \\
\hline
\end{tabular}

*All others include transfer to nursing facility, rehabilitation facility and short, intermediate, long-term care hospital or facility, hospice medical facility, against medical advice, federal health facility. CCl: Charlson Comorbidity Index. 


\begin{tabular}{|c|c|c|c|c|}
\hline \multirow[t]{2}{*}{ Variables } & \multirow{2}{*}{$\begin{array}{l}\text { All patients } \\
\mathrm{N}=5,564,005\end{array}$} & \multirow{2}{*}{$\begin{array}{l}\text { No CPDD } \\
\mathrm{N}=5,552,476\end{array}$} & \multirow{2}{*}{$\begin{array}{l}\text { CPDD } \\
N=11,529\end{array}$} & \multirow{2}{*}{$\begin{array}{l}\mathrm{P}- \\
\text { value }\end{array}$} \\
\hline & & & & \\
\hline Small & 1066647 & $\begin{array}{l}1,064,733 \\
(19.18)\end{array}$ & $\begin{array}{l}1,915 \\
(16.61)\end{array}$ & \\
\hline Medium & 1449112 & $\begin{array}{l}1,446,216 \\
(26.05)\end{array}$ & $\begin{array}{l}2,896 \\
(25.12)\end{array}$ & \\
\hline Large & 3026431 & $\begin{array}{l}3,019,736 \\
(54.39)\end{array}$ & $\begin{array}{l}6,696 \\
(58.08)\end{array}$ & \\
\hline Unknown/missing & 21814 & $21,791(0.39)$ & $23(0.2)$ & \\
\hline \multicolumn{5}{|l|}{$\begin{array}{l}\text { Comorbidities, underlying diagnosis } \\
(\%)\end{array}$} \\
\hline $\begin{array}{l}\text { Diabetes with and without chronic } \\
\text { complications }\end{array}$ & 1172891 & $\begin{array}{l}1,170,925 \\
(21.09)\end{array}$ & $\begin{array}{l}1,966 \\
(17.05)\end{array}$ & $<0.001$ \\
\hline Chronic renal disease & 219750 & $218,945(3.94)$ & $806(6.99)$ & $<0.001$ \\
\hline Coronary artery disease & 664,098 & $\begin{array}{l}662,300 \\
(11.93)\end{array}$ & $\begin{array}{l}1,798 \\
(15.59)\end{array}$ & $<0.001$ \\
\hline Obesity (BMI >30) & 1197789 & $\begin{array}{l}1,196,112 \\
(21.54)\end{array}$ & $\begin{array}{l}1,677 \\
(14.55)\end{array}$ & $<0.001$ \\
\hline Osteoarthritis & 1123674 & $\begin{array}{l}1,121,505 \\
(20.2)\end{array}$ & $\begin{array}{l}2,169 \\
(18.81)\end{array}$ & 0.0002 \\
\hline Rheumatoid arthritis & 188596 & $188,002(3.39)$ & $594(5.15)$ & $<0.001$ \\
\hline Gout & 165796 & $165,286(2.98)$ & $510(4.42)$ & $<0.001$ \\
\hline Avascular necrosis & 34037 & $33,908(0.61)$ & $129(1.12)$ & $<0.001$ \\
\hline Smoking & 991818 & $\begin{array}{l}989,654 \\
(17.82)\end{array}$ & $\begin{array}{l}2,165 \\
(18.78)\end{array}$ & 0.0077 \\
\hline Hemochromatosis & 179 & $179(0)$ & $0(0)$ & 0.5420 \\
\hline Hyperparathyroidism & 5779 & $5,768(0.1)$ & $11(0.1)$ & 0.7202 \\
\hline Hypomagnesemia & 47015 & $46,864(0.84)$ & $151(1.31)$ & $<0.001$ \\
\hline Hypophosphatasia & 2270 & $2,259(0.04)$ & $10(0.09)$ & 0.0089 \\
\hline Charlson comorbidity index (\%) & & & & $<0.001$ \\
\hline 0 & 198275 & $198,073(3.57)$ & $202(1.75)$ & \\
\hline
\end{tabular}

*All others include transfer to nursing facility, rehabilitation facility and short, intermediate, long-term care hospital or facility, hospice medical facility, against medical advice, federal health facility. CCl: Charlson Comorbidity Index. 


\begin{tabular}{|c|c|c|c|c|}
\hline \multirow[t]{2}{*}{ Variables } & All patients & No CPDD & & \multirow{2}{*}{$\begin{array}{l}\mathrm{P}- \\
\text { value }\end{array}$} \\
\hline & $N=5,564,005$ & $N=5,552,476$ & $N=11,529$ & \\
\hline 1 & 817624 & $\begin{array}{l}816,655 \\
(14.71)\end{array}$ & $969(8.4)$ & \\
\hline$\geq 2$ & 4548106 & $\begin{array}{l}4,537,748 \\
(81.72)\end{array}$ & $\begin{array}{l}10,358 \\
(89.84)\end{array}$ & \\
\hline $\mathrm{CCl}$, mean $\pm \mathrm{SD}$, median & $\begin{array}{l}2.77 \pm 3.22 \\
3.00\end{array}$ & $2.77 \pm 3.22,3.00$ & $\begin{array}{l}3.3 \pm 3.43 \\
3.00\end{array}$ & $<0.001$ \\
\hline \multicolumn{5}{|l|}{ Discharge disposition } \\
\hline Home (including home health care) & $\begin{array}{l}3668590 \\
(65.93)\end{array}$ & $\begin{array}{l}3661921 \\
(65.95)\end{array}$ & $6669(57.85)$ & \multirow[t]{2}{*}{$<0.001$} \\
\hline All others * & $\begin{array}{l}1891445 \\
(33.99)\end{array}$ & $\begin{array}{l}1886590 \\
(33.98)\end{array}$ & $4856(42.12)$ & \\
\hline
\end{tabular}

Several coexisting comorbidities were frequently observed among the CPPD patients. Chronic renal disease was evident in $6.9 \%$ of CPPD versus $3.9 \%$ in the non-CPPD $(p<0.001)$ and coronary artery disease in $15.5 \%$ compared to $11.9 \%(p<0.001)$. Rheumatoid arthritis was present in $5.5 \%$ in the CPPD compared to $3.3 \%$ in the non-CPPD $(p<0.001)$, gout in $4.4 \%$ versus $2.9 \%(p<0.001)$ and avascular necrosis in $1.1 \%$ versus $0.61 \%(p<0.001)$. Hypomagnesemia $(p<0.001)$, hypophosphatasia $(p<0.009)$, and history of smoking were more common in the CPPD group $(\mathrm{p}=0.007)$. Notably, non-CPPD patients were more likely to have a BMI $>25$ than CPPD $(p<0.001)$.

Further, CPPD patients had more comorbidities based on the Charlson comorbidity index score, with a mean index of 3.3 compared to 2.7 in the non-CPPD $(p<0.001)$ and a higher proportion of Charlson comorbidity index score above $2(89.8 \%$ CPPD vs $81.7 \%$ non-CPPD; $p<0.001)$ (Table 1$)$. In addition, CPPD patients were more likely to be discharged to another care facility rather than home or with home health care $(p<0.01)$.

There was no significant difference in the in-hospital mortality between the 2 groups, with 5 (0.04\%) deaths of CPPD compared to $3848(0.07 \%)$ in non-CPPD patients $(p=0.29)$ (Table 2$)$. Among all the TKA patients, CPPD was not a significant predictor of in-hospital mortality with an OR 0.52 (95\% Cl: 0.21-1.28) based on a multivariable model and adjusted for age and other variables. 
Table 2

Outcomes and in-hospital complication of patients with CPPD and without CPPD who underwent total knee arthroplasty

\begin{tabular}{|c|c|c|c|c|}
\hline Variables & $\begin{array}{l}\begin{array}{l}\text { All } \\
\text { patients }\end{array} \\
\mathrm{N}= \\
5,564,005\end{array}$ & $\begin{array}{l}\text { Non- CPDD } \\
N=5,552,476\end{array}$ & $\begin{array}{l}\text { CPDD } \\
N=11,529\end{array}$ & $\begin{array}{l}\mathrm{P} \text { - } \\
\text { value }\end{array}$ \\
\hline \multicolumn{5}{|l|}{ Primary Outcomes/Resource utilization } \\
\hline Length of stay (days), mean \pm SD, median & $\begin{array}{l}3.27 \pm \\
3.79,3\end{array}$ & $3.27 \pm 3.79,3$ & $3.48 \pm 3.85,3$ & $<0.001$ \\
\hline $\begin{array}{l}\text { Total hospital charges, mean } \pm \text { SD, median } \\
\text { (US\$) }\end{array}$ & $\begin{array}{l}48,976 \pm \\
63,951 \\
42,332\end{array}$ & $\begin{array}{l}48,975 \pm \\
63942 \\
42,332\end{array}$ & $\begin{array}{l}49,111 \pm \\
59468 \\
42,332\end{array}$ & 0.823 \\
\hline Death during hospitalization & 3852 & $3,848(0.07)$ & $5(0.04)$ & 0.292 \\
\hline \multicolumn{5}{|l|}{$\begin{array}{l}\text { Secondary outcomes/ Post-operative } \\
\text { complications during hospitalization }\end{array}$} \\
\hline \multicolumn{5}{|l|}{ Surgical site infection } \\
\hline Post-operative shock, septic (Sepsis) & 35 & $35(0)$ & $0(0)$ & 0.788 \\
\hline Blood loss and need for transfusions & 983 & $978(0.02)$ & $4(0.03)$ & 0.086 \\
\hline Reoperation & 2854 & $2,839(0.05)$ & $15(0.13)$ & $<0.001$ \\
\hline Thromboembolism & 3779 & $3,774(0.07)$ & $5(0.04)$ & 0.311 \\
\hline Myocardial infraction & 209778 & $\begin{array}{l}209,148 \\
(3.77)\end{array}$ & $630(5.46)$ & $<0.001$ \\
\hline Popliteal artery injury & 240 & $240(0)$ & $0(0)$ & 0.480 \\
\hline Peroneal nerve palsy & 864 & $864(0.02)$ & $0(0)$ & 0.181 \\
\hline
\end{tabular}

The mean length of stay among CPPD patients was 3.4 days compared to 3.2 days in the non-CPPD patients $(p<0.001)$ (Table 2). CPPD patients had significantly higher odds to stay above the median of 3 days based on a multivariable model, adjusted for other comorbidities (OR 1.36; 95\% Cl: 1.30-1.42). Although the mean total hospital charges for TKA in CPPD patients were $\$ 49111$ compared to $\$ 48975$ in the non-CPPD patients, the difference was non-statistically significant $(p=0.82)$ with similar medians, indicating small number of CPPD patients have higher total hospital charges (Table 2). 
Regarding in-hospital complications, myocardial infarction was significantly more common in CPPD patients than non-CPPD (5.4\% vs $3.7 \%, p<0.001)$, as well as the need for reoperation $(0.13 \%$ CPPD vs $0.05 \%$ non-CPPD, $p<0.0001)$. No statistically significant difference was observed between the groups in regard to infections, sepsis, blood loss and need for transfusions, thromboembolism, popliteal artery, and peroneal nerve injury.

Over the study period, the estimated number of TKA performed in non-CPPD patients gradually increased from 495504 in 2006 to 679466 in 2014, with the exception of years 2011 and 2012, in which a decrease number of procedures was noted compared to 2010 (Table 3). No specific pattern was observed among the CPPD patients who underwent TKA.

Table 3

Proportion of total knee arthroplasty (TKA) per year in CPPD patients compared with the non-CPPD patients from 2006 to 2014

\begin{tabular}{|llll|}
\hline Year & $\begin{array}{l}\text { Number of TKA in the non-CPPD } \\
\text { patients }\end{array}$ & $\begin{array}{l}\text { Number of TKA in CPPD } \\
\text { patients }\end{array}$ & $\begin{array}{l}\text { Total number of patients } \\
\text { with TKA }\end{array}$ \\
\hline 2006 & $495504(99.70)$ & $1497(0.30)$ & 497001 \\
\hline 2007 & $550137(99.80)$ & $1122(0.20)$ & 551259 \\
\hline 2008 & $615258(99.78)$ & $1360(0.22)$ & 616617 \\
\hline 2009 & $619751(99.79)$ & $1278(0.21)$ & 621029 \\
\hline 2010 & $657094(99.81)$ & $1246(0.19)$ & 658340 \\
\hline 2011 & $643921(99.82)$ & $1141(0.18)$ & 645062 \\
\hline 2012 & $630154(99.82)$ & $1110(0.18)$ & 631264 \\
\hline 2013 & $661210(99.80)$ & $1335(0.20)$ & 662545 \\
\hline 2014 & $679446(99.79)$ & $1440(0.21)$ & 680886 \\
\hline *Cochran-Armitage trend test. & & \\
\hline
\end{tabular}

\section{Discussion}

This is the first study that analyzed data collected from the largest inpatient database in the US, and several observations warrant further discussion. An important finding was that the in-hospital mortality rate is low and not different between CPPD and non-CPPD patients; therefore, TKA remains a safe procedure. Although the total hospital charges were not different between the 2 groups, CPPD patients had a longer length of stay and were more likely to be discharged to a non-home setting.

TKA is one of the most common orthopedic procedures performed in the US, and in the current study, we found that CPPD accounts for approximately $0.2 \%$ of TKA performed on an annual basis in the US, comprising a small proportion of total TKA surgeries compared to all other causes. A retrospective study 
utilizing data obtained from a Medicare claims database reported that the most common diagnosis associated with TKA was osteoarthritis (94\%) followed by rheumatoid arthritis (3.6\%) and other causes in $2.4 \%$, without commenting if CPPD codes were examined [14]. Given the estimated prevalence of chondrocalcinosis in the general population is between $4 \%-7 \%$, and the results of a published study demonstrating that $20 \%$ of randomly selected patients undergoing TKA found to have CPP crystals in their synovial fluid, it appears CPPD is an underdiagnosed condition and the percentage of TKA related to CPPD might be higher than those recorded $[2,8]$.

We also noted that more than two-thirds of patients had Medicare as their primary insurance payer, and approximately one every five CPPD patients were older than 80 . This is not a surprising finding, given the strong association between aging and CPPD [1, 2]. A small cross-sectional study that evaluated the characteristics of 53 CPPD patients undergoing TKA and compared them with 48 osteoarthritis patients, revealed that CPPD patients were older with a mean age of 70.3 versus $67.5(p=0.037)$ [15].

Several comorbidities were more frequently observed in TKA patients with CPPD, including the 2 most common inflammatory arthritides, rheumatoid arthritis and gout. Similarly, Kleiber et al. analyzed patients' data obtained from the Veterans Affairs (VA) database and reported a positive association between CPPD and gout (OR 2.82), CPPD and RA (OR 1.88) (9). Furthermore, another study examined 4630 synovial fluid specimens for the presence of crystals, and approximately $5 \%$ of patients had mixed crystals, monosodium urate and CPP crystals, indicating the two conditions can coexist [16].

Similar associations between CPPD and other comorbidities such as chronic kidney disease, hypomagnesemia and hypophosphatasia, have been previously reported in studies investigating the relationship between CPPD and coexisting conditions $[5,9,16,18,19]$. Noteworthy, coronary artery disease, smoking and avascular necrosis were also more frequently observed in the CPPD population, and in particular, avascular necrosis is a known condition that leads to bone necrosis and joint destruction requiring joint replacement [20]. Overall, CPPD patients had a greater comorbidity burden based on the Charlson comorbidity index score, and given the older age, these factors may increase the complexity of managing these patients.

Regarding the length of stay and post-discharge site of care, the CPPD patients were more likely to stay longer and be discharged to other care facilities compared to non-CPPD patients. Although there are no post-discharge resource utilization data in the NIS database, the disposition to a non-home setting is most likely associated with increased cost. Healthcare providers and payers should be aware of these findings in order to develop strategies for proper in-hospital rehabilitation to reduce the length of stay and the disposition to a non-home setting.

In the current study, we found that CPPD patients have a low in-hospital mortality rate and similar to the non-CPPD patients. This finding is in line with existing evidence reporting a downward trend in deaths following TKA [21, 22]. A study by Kirskey et al. analyzed the NIS database and noted that the in-hospital mortality decreased from $0.2 \%$ in 1998 to $0.09 \%$ in 2008 [21]. A systematic review of 37 studies reported a decline in the mortality following TKA over a 10-year period, with an estimated 30-day mortality of 
$0.10 \%$ in 2015 [22]. Although there are no studies examining the in-hospital mortality of TKA in CPPD patients, a retrospective study of TKA in gout patients, using data from NIS database, reported an estimated mortality of $0.1 \%$ [23].

In addition, we found that the risk for in-hospital complications such as myocardial infarction was higher among the CPPD patients. In general, TKA patients have a greater risk of myocardial infarction during the first postprocedural month, particularly patients older than the age of 80 and those with underlying coronary artery disease $[24,25]$. This observation might explain the higher risk of myocardial infarction, given the older mean age in the CPPD population and the greater frequency of coronary artery disease, and highlights the importance for awareness and prevention of this devastating complication.

There are several limitations in the interpretation of the study's results. First, there are no available longitudinal data, such as discharge complications, outpatient resource utilization, post-discharge mortality, and due to the design of the cohort study, there is a risk of confounding bias. Additionally, the database does not provide information about patient-reported outcomes, laboratory studies, and medications, variables that might influence the outcomes. Our study has several strengths. The nationwide study design is more representative of the population, and the large sample size provides more reliable and accurate results.

\section{Conclusions}

The current study sheds light into the association between TKA and CPPD. We demonstrated that CPPD patients who underwent TKA were more likely to be older, white, male, and have a higher comorbidity burden than the non-CPPD. Several comorbidities were associated with increased odds for TKA in CPPD, and in-hospital complications, such as myocardial infarction and reoperation, were more common in CPPD patients. Although there was no significant difference in the in-hospital mortality, the CPPD patients were more likely to have longer hospital stay and discharge to inpatient/rehabilitation facility.

\section{Abbreviations}

CPPD

calcium pyrophosphate deposition disease

calcium pyrophosphate dihydrate (CPP)

TKA

total knee arthroplasty

NIS

National Inpatient Sample

HCUP

Healthcare Cost and Utilization Project

ICD-9

International Classification of Diseases code, ninth revision (ICD-9). 


\section{Declarations}

\section{Ethics approval and consent to participate}

NIS database is a publicly available databasein the USA including de-identifed discharge data. An ethics committee approval was not required for the study as no personally identifiable information was used.

\section{Consent for publication}

No consent was obtained given the data provided were de-identified.

\section{Availability of data and materials}

Datasets are available at the Agency for Healthcare Research and Quality (AHRQ's) “Healthcare Cost and Utilization Project (HCUP)". Link: https://www.hcup-us.ahrq.gov. Data can be obtained and used by signing a Data Use Agreement and by completing an online Data Use Agreement training session.

\section{Competing interests}

The authors declare that they have no competing interests,

\section{Funding}

This study was supported by funding provided by the University of Cyprus. The funding body did not involve in the study design, collection, data analysis, interpretation of data and in the writing of the manuscript.

\section{Authors' contributions}

$\mathrm{KP}$ designed the study protocol. $\mathrm{BB}$ retrieved and analyzed the patient data. $\mathrm{KP}, \mathrm{BB}$ and $\mathrm{MH}$ interpreted the patient data. All authors had a major contributor in writing the manuscript. All authors read and approved the final manuscript.

\section{Acknowledgements}

We are grateful to Dr. Ann Rosenthal for reviewing this manuscript and providing supportive comments.

\section{References}

1. Rosenthal AK, Ryan LM. Calcium Pyrophosphate Deposition Disease. N Engl J Med. 2016 30;374:2575-84.

2. Richette $P$, Bardin T, Doherty M. An update on the epidemiology of calcium pyrophosphate dihydrate crystal deposition disease. Rheumatology (Oxford). 2009;48:711-5. 
3. Parperis K, Carrera G, Baynes K, Mautz A, Dubois M, Cerniglia R, et al. The prevalence of chondrocalcinosis (CC) of the acromioclavicular (AC) joint on chest radiographs and correlation with calcium pyrophosphate dihydrate (CPPD) crystal deposition disease. Clin Rheumatol. 2013;32:13836.

4. Felson DT, Naimark A, Anderson J, Kazis M, Castelli W, Meenan RF. The prevalence of knee osteoarthritis in the elderly. The Framingham Osteoarthritis Study. Arthritis Rheum. 1987;30:914-8.

5. Jones AC, Chuck AJ, Arie EA, Green DJ, Doherty M. Diseases associated with calcium pyrophosphate deposition disease. Semin Arthritis Rheum. 1992; 22:188-202.

6. Zhang W, Doherty M, Bardin T, Barksova V, Guerne PA, Jansen TL, et al. European League Against Rheumatism recommendations for calcium pyrophosphate deposition. Part I: terminology and diagnosis. Ann Rheum Dis. 2011;70:563-70.

7. Parperis K, Papachristodoulou E, Kakoullis L, Rosenthal AK. Management of calcium pyrophosphate crystal deposition disease: A systematic review. Semin Arthritis Rheum. 2020;51:84-94.

8. Derfus BA, Kurian JB, Butler JJ, Daft LJ, Carrera GF, Ryan LM, et al. The high prevalence of pathologic calcium crystals in preoperative knees. J Rheumatol. 2002;29: 570-4.

9. Kleiber Balderrama C, Rosenthal AK, Lans D, Singh JA, Bartels CM. Calcium Pyrophosphate Deposition Disease and Associated Medical Comorbidities: A National Cross-Sectional Study of US Veterans. Arthritis Care Res (Hoboken). 2017;69:1400-6.

10. Willems JH, Rassir R, Sierevelt IN, Nolte PA. There is no difference in postoperative pain, function and complications in patients with chondrocalcinosis in the outcome of total knee arthroplasty for endstage osteoarthritis. Knee Surg Sports Traumatol Arthrosc. 2020;28:2970-9.

11. Healthcare Cost and Utilization Project (HCUP). Overview of the National (Nationwide) Inpatient Sample (NIS). https://www.hcup-us.ahrq.gov/nisoverview.jsp. Accessed 29 December 2020.

12. Bartels $\mathrm{CM}$, Singh JA, Parperis $\mathrm{K}$, Huber K, Rosenthal AK. Validation of administrative codes for calcium pyrophosphate deposition: a Veterans Administration study. J Clin Rheumatol. 2015;21:189-92.

13. Deyo RA, Cherkin DC, Ciol MA. Adapting a clinical comorbidity index for use with ICD-9-CM administrative databases. J Clin Epidemiol. 1992;45:613-9.

14. Mahomed NN, Barrett J, Katz JN, Baron JA, Wright J, Losina E. Epidemiology of total knee replacement in the United States Medicare population. J Bone Joint Surg Am. 2005;87:1222-8.

15. Viriyavejkul P, Wilairatana V, Tanavalee A, Jaovisidha K. Comparison of characteristics of patients with and without calcium pyrophosphate dihydrate crystal deposition disease who underwent total knee replacement surgery for osteoarthritis. Osteoarthritis Cartilage. 2007;15:232-5.

16. Jaccard YB, Gerster JC, Calame L. Mixed monosodium urate and calcium pyrophosphate crystalinduced arthropathy. A review of seventeen cases. Rev Rhum Engl Ed. 1996;63:331-5.

17. Richette P, Ayoub G, Bardin T, Bouvet S, Orcel P, Badran AM. Hypomagnesemia and chondrocalcinosis in short bowel syndrome. J Rheumatol. 2005;32:2434-6. 
18. O'Duffy JD. Hypophosphatasia associated with calcium pyrophosphate dihydrate deposits in cartilage. Report of a case. Arthritis Rheum. 1970;13:381-8.

19. Rho YH, Zhu Y, Zhang Y, Reginato AM, Choi HK. Risk factors for pseudogout in the general population. Rheumatology (Oxford). 2012;51:2070-4.

20. Mont MA, Marker DR, Zywiel MG, Carrino JA. Osteonecrosis of the knee and related conditions. J Am Acad Orthop Surg. 2011;19:482-94.

21. Kirksey M, Chiu YL, Ma Y, Della Valle AG, Poultsides L, Gerner P, et al. Trends in in-hospital major morbidity and mortality after total joint arthroplasty: United States 1998-2008. Anesth Analg. 2012;115:321-7.

22. Berstock JR, Beswick AD, López-López JA, Whitehouse MR, Blom AW. Mortality After Total Knee Arthroplasty: A Systematic Review of Incidence, Temporal Trends, and Risk Factors. J Bone Joint Surg Am. 2018;100:1064-70.

23. Singh JA, Cleveland JD. Gout is associated with increased healthcare utilization after knee arthroplasty. Ann Rheum Dis. 2019;78:1146-8.

24. Lu N, Misra D, Neogi T, Choi HK, Zhang Y. Total joint arthroplasty and the risk of myocardial infarction: a general population, propensity score-matched cohort study. Arthritis Rheumatol. 2015;67:2771-9.

25. Belmont PJ Jr, Goodman GP, Kusnezov NA, Magee C, Bader JO, Waterman BR, et al. Postoperative myocardial infarction and cardiac arrest following primary total knee and hip arthroplasty: rates, risk factors, and time of occurrence. J Bone Joint Surg Am. 2014;96:2025-31. 